\title{
SPACIAL ORIENTATION OF CHILDREN WITH VISUAL IMPAIRMENTS IN FAMILIES
}

\author{
AUTHORS' DATA: \\ Sona Davtyan, $\mathrm{PhD}$ in Education, Associated professor \\ Chair of Special pedagogy and psychology, ASPU \\ Lecturer \\ Contacts: d-sona@mail.ru
}

\begin{abstract}
The current study presents the main directions, theoretical and practical ways of development of spatial orientation of the preschool children with visual impairments, and its necessity within the family life condition. The aim of the research is to elaborate means, methods and conditions of their application for spatial orientation development of the preschool children with visual impairments for their parents and families. As a result, parents of preschool children with visual impairments were provided with appropriate knowledge and skills.
\end{abstract}

Key words: preschool children with visual impairment, development, orientation, mobility, skills, education, family.

\section{INTRODUCTION}

Children with visual impairment rarely express independence, self-advocacy and selfdirection skills in their behavior. Visual impairment, inadequate attitude of parents, teachers, and peers toward a blind or low vision child have a negative influence on the sense of security and selfassessment of the ability to make everyday decisions independently (Bardin \& Lewis, 2008). Many authors state that children with visual impairment have difficulties in independent and reasonable behavior, they find it difficult to predict an outcome before making a decision, they rarely apologize for their mistakes, and they cannot control anger. Most authors point out that the impairment and its consequences as well as inadequate attitude of parents and teachers toward children with visual impairment, have a negative influence on the sense of security and self-assessment of abilities to 
make independent decisions in everyday life (Bardin \& Lewis, 2008; Avramidis \& Norwich, 2010; Andjelkovic, 2017).

Orientation is the ability of the visually impaired child to perceive and understand his/her position and location within a given environment. Children learn about their environment as they move through and about people and objects, sizes, shapes, and distances as they interact. For typically developing children the senses of sight and hearing provide the greatest motivation for exploration. These children use their vision and hearing to gather information about their surroundings while growing, while understanding of their own bodies and their own capabilities of movement. The sight of toys or people and the sounds of voices or objects encourage them to move and discover. As they do so, they gather, recognize, and interpret an amazing array of sensory information (Sapp \& Hatlen, 2010).

Mobility is the ability to move about within a given environment. These abilities do not suddenly appear at a specific time or age, but have an underlying conceptual foundation which begins at birth. For visually impaired infants, many factors contribute to the quality of these emerging conceptual foundations: the quantity/quality of available vision; whether that vision will remain the same, improve, or deteriorate; whether there are other disabilities (hearing, motor, tactual defensiveness, impaired senses of smell or taste); alertness/receptivity. Initial mobility factors are largely motor-based, and depend to a great extent on the development of the motor system. Milestone skills such as head control, sitting unsupported, independent hand/arm use (as in grasping and reaching), creeping/crawling, standing alone, and walking independently are all pre-mobility skills.

It is known that preschool age plays an important role in general development of both typically developing children and children with visual impairments (Avramidis \& Norwich, 2010) Profound and partial visual impairments complicate spatial orientation of these children. Therefore, the development of the ability of spatial orientation of preschool children with visual impairments in family has an exceptionally important value. At the same time, the insufficient scrutiny and elaboration of the issue significantly impede the works of formation and development of abilities of spatial orientation of preschool children in family. The content of the work aimed at the development of abilities of the spatial orientation of preschool children with visual impairments in family settings is not studied, there is no elaborated sample program for formation and development of the ability of micro and macro spatial orientation of preschool children with visual 
impairments. That's why a comprehensive study of these issues and the experimental elaboration of special means, methods, conditions of their application and a sample program for formation and development of abilities of spatial orientation of preschool children with visual impairments in family settings is very urgent, theoretically and practically significant.

The aim of the research is to elaborate means, methods and conditions of their application for development of the ability of the spatial orientation of preschool children with visual impairments in family settings.

The objectives of the research are the following:

1. To study the level of scrutiny of the issue theoretically and practically;

2. To study the ability of spatial orientation of preschool children with visual impairments;

3. To elaborate special means, methods and conditions of their application for development of abilities of the spatial orientation of preschool children with visual impairments in family settings;

4. To experimentally justify the efficiency of application of the recommended approaches.

\section{METHOD AND PROCEDURE}

The participants of the currents study are parents of preschool age children visiting preschool setting functioning within the frame of Yerevan school N14 for children with visual disorders. As total 75 parents took part in this study. The universal sampling method was used while organizing the selection procedure of parents. The quantitative questionnaire was circulated to all the parents to understand the basic challenges children feel while spatial development and orientation.

Questionnaires later on were analyzed using Exel analytical tool. The data and parameters for each analysis were implemented, and the tool used the appropriate statistical functions to calculate and display the results.

\section{RESULTS AND DISCUSSION}

After analyzing the data, it became obvious that the majority of parents (95\%) are sure that their child will never be able to orientate in micro and macro environments, and will always have 
difficulties in developing independence, self-advocacy and self-direction skills in their behavior. So, based on this, it was decided to create a program in order to raise awareness of parents regarding the abilities of their children with visual impairments.

When a child cannot access his world efficiently through his vision, he must learn to use his other senses more effectively (Davtyan, 2016). Systematic instruction is needed to develop the other senses for use in travel and finding things in the environment. The child must understand that some of the sounds and smells and textures he experiences can be used as permanent markers (landmarks) to let him know where he is in the world. Other pieces of information may be there sometimes and not at other times (clues) such as the sound of the water fountain. Developing sensory awareness is critical for the child with visual impairments or blindness. Most children with visual impairments are capable of learning routes in familiar environments.

They learn to use landmarks and clues to help them know where they are along a particular route. They learn specific adaptations to aid them in their movement. These might include understanding that tactual markers on doorways identify the gym or the restroom, using an adaptive mobility device or a cane to identify obstacles and drop-offs, or locating a street sign using a monocular. A primary goal of orientation and mobility training is to help each child with visual impairments achieve independent movement to as great a degree as possible. Independent movement is critical for all children with visual impairments. Orientation and Mobility specialists are trained to provide instruction which will enable children with visual impairments to reach their highest level of independence.

The theoretical significance of the study is determined by the theoretical statement of efficiency of recommended approaches to formation of the ability of spatial orientation of preschool children with visual impairments in family settings and by the research results.

Many parents choose to homeschool their children because they cannot always guarantee that their child will receive an adequate education through the public school system. For parents with blind or visually impaired children, homeschooling may be even more appealing because they can provide their child with the attention and additional resources that they will need to succeed in a learning environment (Bardin \& Lewis, 2008). In order to homeschool a blind or visually impaired child you should establish yourself as a home educator, provide your child with assistive technology, modify the learning experience to suit the needs of your child, and provide your child with an opportunity to socialize with other children. Spatial orientation is a person's skill in using 
the information received through their senses to determine their position in space and their destination in relation to significant objects in the environment. In the context of visual impairment, this term refers more specifically to knowledge of distances and directions that relate to objects in the environment and have been observed or memorized, and the ability to commit these spatial relationships to memory when they change as the person proceeds. Spatial skills are defined by putting in place and using spatial relations between a particular place and oneself (e.g. in a given fixed position) or between different places (independently of one's own position).

Orientation integrates perceptual and cognitive learning. Integrating the sensory information needed for orientation requires conceptual development that includes among others, body scheme, the body-to-object relationship, spatial updating, the object-to-object relationship, the environment and time, as well as conceptual understanding of objects.

It is very important to state, that spatial orientation may be affected by dysfunction of any of the basic sensory systems (touch, proprioceptive, vestibular, olfactory, auditory or visual). The development of orientation skills and the construction of a mental representation of the environment are also related to various cognitive faculties such as attention capacity, short-term, long-term and topographic memory, and language skills (Davtyan, 2018; Davtyan, 2018).

At an integration level, mental representation of space involves localizing the stimulus, spatial memory, inference skills, and using symbolic representations and cognitive maps.

So practical strategies for families formulated as follows:

- Provide opportunities for your child to explore all areas of his or her environment, particularly the home. Help the child locate stationary landmarks that provide reference points. For example, a child may know that he is in his bedroom after locating his dresser with the "special" handles. Be sure to allow him to find this dresser so he will know when he is in the bedroom.

- Let your child experience a variety of surfaces such as carpet, tiled floors, vinyl flooring, grass, sidewalks.

- Allow your child to participate fully in activities. For example, if he wants to play with toys, help him go to the place where the toys are located and select the toy that interests him. Travel back to the play area together. This process allows him to understand his environment more completely, as compared to having the toys simply brought to him. 
- Make full use of "reference points," those clues that help us know where we are. We have all experienced being lost in an unfamiliar city, only to become "reoriented" once we locate a familiar landmark. Similarly, children who are deaf-blind need to learn to use reference points to help them stay oriented in their environment. Reference points can be auditory, tactile or visual.

- Encourage your child to travel as independently as possible. If he can walk independently, allow him to do so. If he is learning to walk with a guide, don't hold his hand and pull him along with you. If he is capable of reaching out to locate a desired toy, don't allow it to "magically appear" by bringing it to him.

- Make use of physical boundaries so the child can better understand his surroundings. It is much easier to comprehend a play area bounded by wall dividers or bookshelves than an arbitrary space in the middle of a large room.

- Provide opportunities for the child to solve problems on his or her own. Refrain from rescuing him or her prematurely.

- Help a child associate familiar toys and objects with the environments in which they may be used. For example, show him the washcloth before walking to the bathroom for a bath, or the ball before traveling to the school gymnasium (Davtyan, 2016; Davtyan, 2018).

\section{CONCLUSION}

These the organizing and passing the numbers made theoretical approaches formation of the spatial side detection capabilities and the development of preschool child with visual impairment, and the point of view and practical ways are aimed at improving that work in a family and raising awareness about the child's abilities. The formation and development of spatial side detection capabilities in a family, with active participation of parents, trust and belief towards the child is the only prerequisite for positive results.

\section{REFERENCE LIST}

1. Andjelkovic, M. (2017) Conceptual skills in persons with visual impairment, Specijalna edukacija i rehabilitacija (Beograd), Vol. 16, br. 1. 9-33. 
2. Avramidis, E., \& Norwich, B. (2010) Teachers' attitudes towards integration/inclusion: A review of literature'. European Journal of Special Needs Education, 17(2), 129-147.

3. Bardin, J. A., Lewis, S. (2008) A survey of the academic engagement of students with visual impairment general education classes. Journal of Visual Impairment \& Blindness, 102(8), 472483.

4. Davtyan, S. R. (2018) Prostranstvennaya orientirovka u doshkolnikov s narusheniyami zreniya $\mathrm{v}$ usloviyakh semyi (Spatial orientation in preschool children with visual impairment in a family). Problemi I perspektivi razvitioya obrazovaniya, II Vserossiyskaya nauchnoprakticheskaya konferenciya (s mejdunarodnim uchastiem, g.o. Orekhovo-Zuevo, s. 21-23.

5. Davtyan, S. R. (2016) Tesoghutyan khangarum unecogh nakhadprocakanneri taracakan koghmnoroshman karoghutyunneri dzevavorumn yntaniqum (Developing spatial orientation capabilities of preschoolers with visual impairments in the family). Hayastani Hanrapetutyan social-tntesakan kayun zargacman himnakhndirneri gitakan hodvacneri zhoghovatsu, Yerevan 1/23/. - ej 374-378

6. Davtyan, S. R. (2018) Tesoghutyan khangarum unecogh nakhadprocakanneri taracakan koghmnoroshman karoghutyunneri dzevavorman ev zargacman mijocnern yntaniqum (Assessment and Development of Spatial Orientation Skills of Preschoolers with Visual Impairment in the Family), Usumnametodakan dzernark, "Nahapet" hratarakchutyun, Yerevan, 47 ej

7. Sapp, W., Hatlen, P. (2010) The expanded core curriculum: Where we have been, where we are going, and how we can get there. Journal of Visual Impairment \& Blindness, 104, 338-348 